\title{
Considerações sobre o uso de polígonos de amostragem em classificações supervisionadas de imagens de satélite
}

\author{
Considerations for using sampling polygons in supervised satellite image classifications
}

\author{
Paulo Roberto Fitz \\ Doutor - Universidade Federal da Grande Dourados, Brasil \\ paulofitz@ufgd.edu.br; paulo.fitz@gmail.com
}

\begin{abstract}
Resumo
A dinâmica do espaço geográfico ou natural pode ser estudada através de diferentes métodos e técnicas. Uma das maneiras diz respeito ao uso das técnicas de sensoriamento remoto para a geração de mapas temáticos a partir da classificação de imagens de satélite. Em geral, são utilizadas classificações supervisionadas, uma vez que a acurácia destas vai depender da percepção e experiência do usuário, desde que obedecidas algumas regras básicas. A preocupação deste estudo recaía na definição da quantidade de amostras referentes à área trabalhada para sua classificação. A amostragem dada pelas áreas de treinamento deveria relacionar-se à assinatura espectral relativa às mesmas, ou seja, às porções previamente escolhidas como modelos para a obtenção das classes de uso do solo, ou de cobertura da terra. A ideia era a de confrontar os resultados obtidos nesta amostragem, que contemplava cerca de $2 \%$ da área utilizada em procedimento anterior, com os daquela simulação. A hipótese presumia que deveria haver uma tendência de estabilização nos dados, de acordo com o incremento de áreas de treinamento dadas por polígonos de amostragem, inferior à indicada pela experimentação anterior. As simulações realizadas, entretanto, não confirmaram a hipótese apresentada, e os resultados obtidos indicaram um equilíbrio bastante próximo daquele encontrado em uma área bem maior.
\end{abstract}

Palavras-chave: sensoriamento remoto, imagens de satélite, classificação supervisionada, áreas de treinamento, polígonos de amostragem. QGIS.

\begin{abstract}
The dynamics of geographical or natural space can be studied through different methods and techniques. One way is to use remote sensing techniques to generate thematic maps from the classification of satellite images. In general, supervised classifications are used, since their accuracy will depend on the user's perception and experience, as long as some basic rules are obeyed. The concern of this study was to define the number of samples referring to the area worked for its classification. The sampling given by the training areas should be related to their spectral signature, i.e., the portions previously chosen as models for obtaining land use or land cover classes. The idea was to compare the results obtained in this sample, which included about $2 \%$ of the area used in the previous procedure, with those of that simulation. The hypothesis assumed that there should be a stabilisation trend in the data, according to the increment of training areas given by sampling polygons, lower than indicated by previous experimentation. The simulations performed, however, did not confirm the hypothesis presented, and the results obtained indicated a balance very close to that found in a much larger area.
\end{abstract}

Keywords: remote sensing, satellite imagery, supervised classification, training areas, sampling polygons. QGIS. 


\section{INTRODUÇÃO}

Quando se trabalha com a dinâmica do espaço geográfico ou natural, diferentes métodos e técnicas podem ser empregados. Dentre as mais diversas ferramentas, o uso de imagens de satélite para a realização de estudos e análises tem se mostrado bastante eficiente. Para facilitar a visualização e a compreensão dos fenômenos que ocorrem na superfície terrestre, são realizadas composições coloridas e "falsa-cor.

A confecção de mapas temáticos de uso e ocupação da terra a partir de classificações de imagens é um dos exemplos mais comuns relacionados à aplicação das técnicas de sensoriamento remoto. A classificação de imagens, ou seja, conforme Fitz (2008, p. 129) apresenta, "a identificação de determinados elementos nelas presentes pela associação de cada um de seus pixels a uma determinada classe preestabelecida" pode ser realizada a partir de diversos algoritmos disponíveis em diferentes softwares. As classificações podem ser supervisionadas, quando o usuário interfere diretamente na mesma através da escolha das categorias de amostragem; e não supervisionadas, quando a classificação é automática, ou seja, o usuário somente define o número de classes a serem reconhecidas. (FITZ, 2008; CRÓSTA, 1999; RICHARDS; JIA, 2006; CONGALTON; GREEN, 2009)

Nem sempre os resultados das classificações são satisfatórios, notadamente quando utilizados classificadores não supervisionados. Neste sentido, em geral, opta-se por utilizar classificações supervisionadas, uma vez que a acurácia destas vai depender da percepção e experiência do usuário, desde que obedecidas algumas regras básicas. Diversos autores como Aronoff (1985), Richards; Jia (2006), Congalton; Green (2009), Eastman (1998), Crósta (1993) e Fitz et al. (2019) trabalharam o assunto. Para sintetizar as ideias apresentadas pelos autores, podem-se indicar certos preceitos que deverão ser contemplados pelo usuário quanto à:

1. definição do número de classes de amostragem;

2. escolha das unidades de amostragem, que podem ser apresentadas por um pixel, um cluster de pixels, um polígono, ou um cluster de polígonos;

3. escolha da quantidade de amostras relativas à área, dada pela quantidade de pixels representativos correspondentes a cada classe;

4. definição da distribuição espacial das amostras na área de trabalho.

A preocupação deste estudo recaía na definição da conveniente quantidade de amostras relativas à área trabalhada. É sabido que a amostragem dada pelas áreas de treinamento deve relacionar-se à assinatura espectral relativa às mesmas, ou seja, às porções previamente escolhidas como modelos para a obtenção das classes de uso do solo, ou de cobertura da terra. A partir daí o software se encarregará de agrupar pixels semelhantes de acordo com as áreas de treinamento 
adotadas para a geração de um mapa temático.

Para a definição de uma quantidade de amostras, Fitz et al. (2019, p. 340) sugerem “a adoção de, pelo menos, cinquenta polígonos amostrais por classe, que configurem, da melhor forma possível, a região a ser classificada. Estas áreas de treinamento deverão abarcar todas as características relativas às classes a serem adotadas".

A utilização de tantas áreas de treinamento estaria vinculada à superfície utilizada no trabalho realizado pelos autores, a qual correspondia a pouco menos de 24,5 mil quilômetros quadrados. Assim, neste estudo, foi utilizada uma pequena fração da área então trabalhada (478,295 $\mathrm{km}^{2}$ ) para observar o comportamento quando da adoção de uma grande quantidade de amostras em uma área bem menor, a saber, o Município de Mundo Novo, situado no sul do Estado do Mato Grosso do Sul. A hipótese presumia que deveria haver uma tendência de estabilização nos dados, de acordo com o incremento de áreas de treinamento dadas por polígonos de amostragem, inferior às cinquenta unidades sugeridas por Fitz et al. (2019, p. 340), uma vez que este recorte correspondia a cerca de $2 \%$ da área então trabalhada pelos autores.

\section{METODOLOGIA}

Num primeiro momento foi importado o arquivo vetorial correspondente ao município de Mundo Novo, MS, em formato shape, desde o site do IBGE $^{1}$. Em seguida, a execução do trabalho se deu a partir do descarregamento gratuito dos arquivos com imagens que cobriam toda a região, desde os sites da USGS (United States Geological Survey - Pesquisa Geológica dos Estados Unidos) e do INPE (Instituto Nacional de Pesquisas Espaciais) do Brasil. Optou-se pelo uso das imagens do sensor OLI (Operational Land Imager) do Landsat 8, de 29/08/2018, data que coincide, grosso modo, com a época de colheita e preparo para o plantio de cultivos na região.

As imagens foram recortadas de acordo com o arquivo shape com o uso do software QGIS versões 2.18 e 3.4. Em seguida, foram realizadas composições coloridas falsa-cor (5R-4G-3B) para posterior classificação das mesmas e elaboração de mapas temáticos. Dessa maneira, a complexidade da natureza deverá ser segmentada de acordo com a escala definida pelo usuário. Conforme é colocado por Lang (2009, p. 41), com relação ao aumento de resolução dos sistemas modernos, a característica principal na segmentação de imagens multiespectrais está relacionada a uma "discretização da informação altamente complexa em objetos elementares". A figura 1 mostra a composição colorida realizada e a localização do município de Mundo Novo em relação ao estado do Mato Grosso do Sul e ao Brasil.

\footnotetext{
${ }^{1}$ https://mapas.ibge.gov.br/bases-e-referenciais/bases-cartograficas/malhas-digitais 


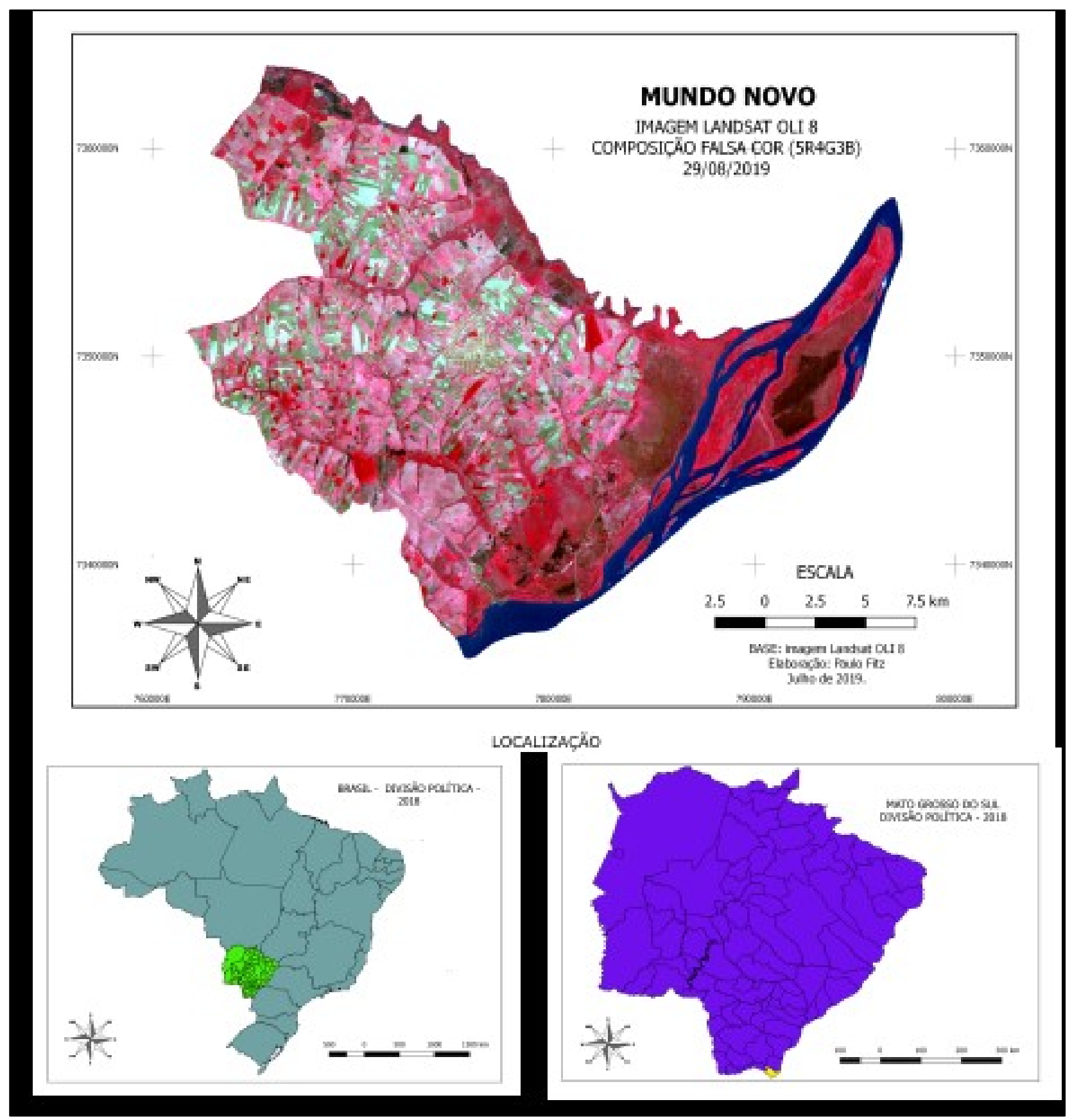

Figura 1 - Mundo Novo: localização

Fonte: Autoria própria, 2019.

O Manual Técnico de Uso da Terra do IBGE exibe o "Sistema básico de classificação da cobertura e do uso da terra - SCUT". Nele, a cobertura da terra é entendida como "os elementos da natureza como a vegetação (natural e plantada), água, gelo, rocha nua, areia e superfícies similares, além das construções artificiais criadas pelo homem, que recobrem a superfície da terra." (IBGE, 2013, p. 44. Grifo dos autores). Posteriormente, é destacado que dados de sensoriamento remoto podem ser correlacionados com a cobertura da terra e mapear o tema a partir da interpretação dos dados a ela relativos.

Baseado nestes apontamentos, as classes utilizadas neste experimento foram adaptadas 
desde as indicações apresentadas no referido manual, cuja sistemática é dividida em três níveis: I. classes; II. subclasses; e III. unidades. O nível I desta classificação é subdividido em cinco outras classes: 1 - Áreas Antrópicas não Agrícolas; 2 - Áreas Antrópicas Agrícolas; 3 - Áreas de Vegetação Natural; 4 - Água; 5 - Outras áreas.

Levando em consideração esta perspectiva, o presente estudo fez uso de somente 3 (três) classes de uso, a saber:

- Classe 1: corpos d'água, que inclui todos os conjuntos de feições que caracterizem acumulação de água, como rios, lagos e açudes;

- Classe 2: áreas antropizadas, que dizem respeito às feições reconhecidas como aquelas alteradas pela ação do homem;

- Classe 3: cobertura vegetal "original", que engloba, além da vegetação nativa composta principalmente por mata atlântica e de várzea, porções com plantações de florestas de espécies exóticas, uma vez que, nesta escala, torna-se impraticável distinguir a introdução de tais matas.

As classificações foram realizadas a partir do algoritmo dzetsaka disponibilizado pelo QGIS, um método de classificação supervisionada desenvolvido por Nicolas Karasiak ${ }^{2}$, o qual utiliza um classificador GMM (Gaussian Mixture Model), ou Modelo de Mistura Gaussiana. Como base de análise, foi utilizada a composição falsa-cor 5R-4G-3B.

As áreas de treinamento foram delimitadas por polígonos de amostragem que pudessem representar da melhor forma possível a classe escolhida. Cada conjunto de polígonos representativos deveria englobar, no mínimo, trinta pixels, uma vez que, conforme Eastman (1998, p. 133) "o número de pixels de cada conjunto de treinamento (i.e., todas as áreas de treinamento para uma única classe de cobertura do solo) não deveria ser menor do que dez vezes o número de bandas".

Inicialmente foi realizada uma classificação com um conjunto contemplando somente um polígono relativo à cada classe escolhida, a saber, corpos d'água; áreas antropizadas; e áreas com cobertura vegetal "original”. Em seguida, foram agregados mais três polígonos, um para cada uma destas classes, totalizando seis áreas de treinamento (três clusters com dois polígonos). O mesmo procedimento foi sendo adotado de tal forma que os polígonos representativos eram adicionados um a um conforme as classes predeterminadas até atingir um total de sessenta clusters, cada um com três classes, ou seja, cento e oitenta áreas de treinamento.

Nesse sentido, teoricamente, deveria haver uma tendência de estabilização nos dados de

\footnotetext{
${ }^{2}$ https://plugins.qgis.org/plugins/dzetsaka/
} 
acordo com o incremento de áreas de treinamento dadas por polígonos de amostragem. No limite, um número infinito de polígonos representaria com exatidão as diferentes classes.

As áreas e a respectiva quantidade de pixels das três classes, para cada simulação, foram calculadas através do plugin r.report do QGIS. Após a geração destes dados, os resultados foram exportados e retrabalhados em uma planilha Excel, onde foram confeccionados gráficos relativos a cada ensaio. A ideia era a de relacionar as áreas das classes dos mapas temáticos gerados com a quantidade de polígonos utilizados como amostragem.

Os mesmos procedimentos foram realizados para uma superfície retangular, com $24.461,325 \mathrm{~km}^{2}$ de área, que abrangesse toda a região conhecida por "Conesul”, onde o município de Mundo Novo está inserido (MATO GROSSO DO SUL, 2009). Somente ao final da modelagem, após a geração do mapa temático de toda a região, é que o contorno do município foi recortado para comparação com o experimento que utilizou polígonos amostrais somente dentro da área abrangida pelo contorno do município em questão.

\section{RESULTADOS, ANÁLISES E DISCUSSÕES}

De certa forma, ao contrário da hipótese conjecturada, os resultados obtidos não diferiram muito daqueles obtidos por Fitz et al. (2019) quando envolveram uma área bem superior. As maiores variações se deram quando da introdução dos dados amostrais iniciais e uma estabilização mais consistente ocorreu somente a partir da $47^{\text {a }}$ (quadragésima sétima) amostra para o caso da classe corpos d'água, e de cerca de 30 (trinta) polígonos amostrais para o caso das áreas antropizadas, bem como para a classe cobertura vegetal "original”.

Os gráficos relativos às simulações realizadas são apresentados a seguir. As figuras 2, $3 \mathrm{e}$ 4, respectivamente, permitem constatar os comportamentos das curvas representativas para as classes corpos d'água, áreas antropizadas e cobertura vegetal "original”.

As figuras 2, 3 e 4 buscaram representar as simulações do número de polígonos amostrais em relação às áreas correspondentes, em quilômetros quadrados. A área total, de 478,295 km², correspondia a 531.439 pixels na representação temática. As variações iniciais percebidas diziam respeito a ajustes relativos aos atributos designados para cada uma das classes. Assim sendo, num primeiro momento, por exemplo, áreas contemplando pastagens ou lavouras em terrenos baixos, com bastante umidade, poderiam confundir-se com áreas de banhados. 


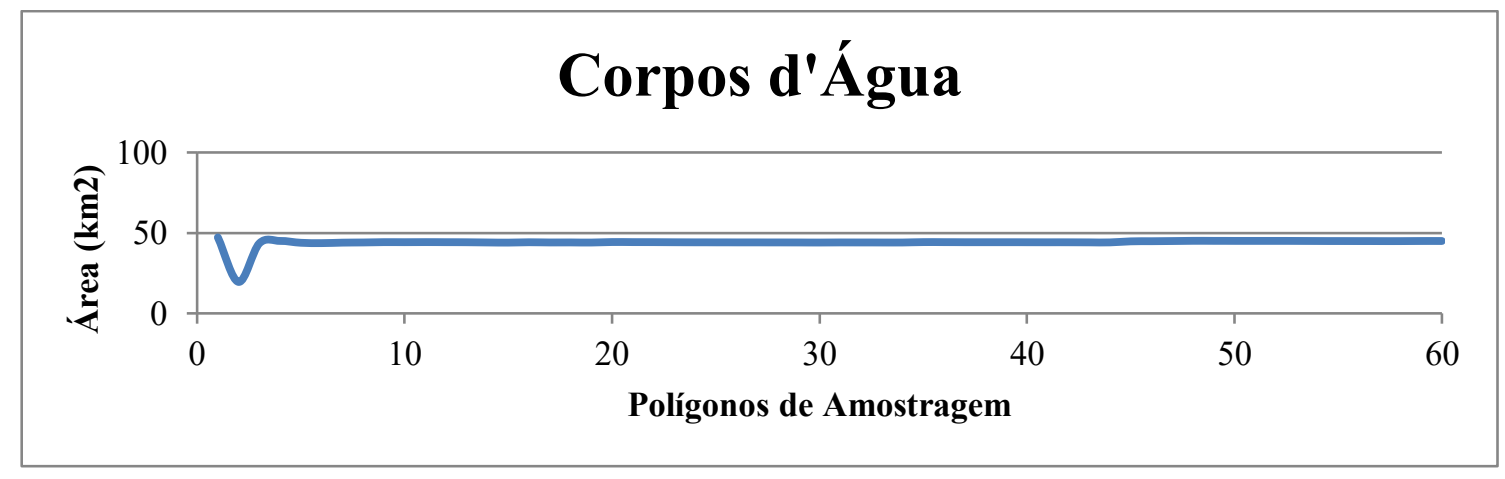

Figura 2 - Corpos d'água

Fonte: Autoria própria, 2019.

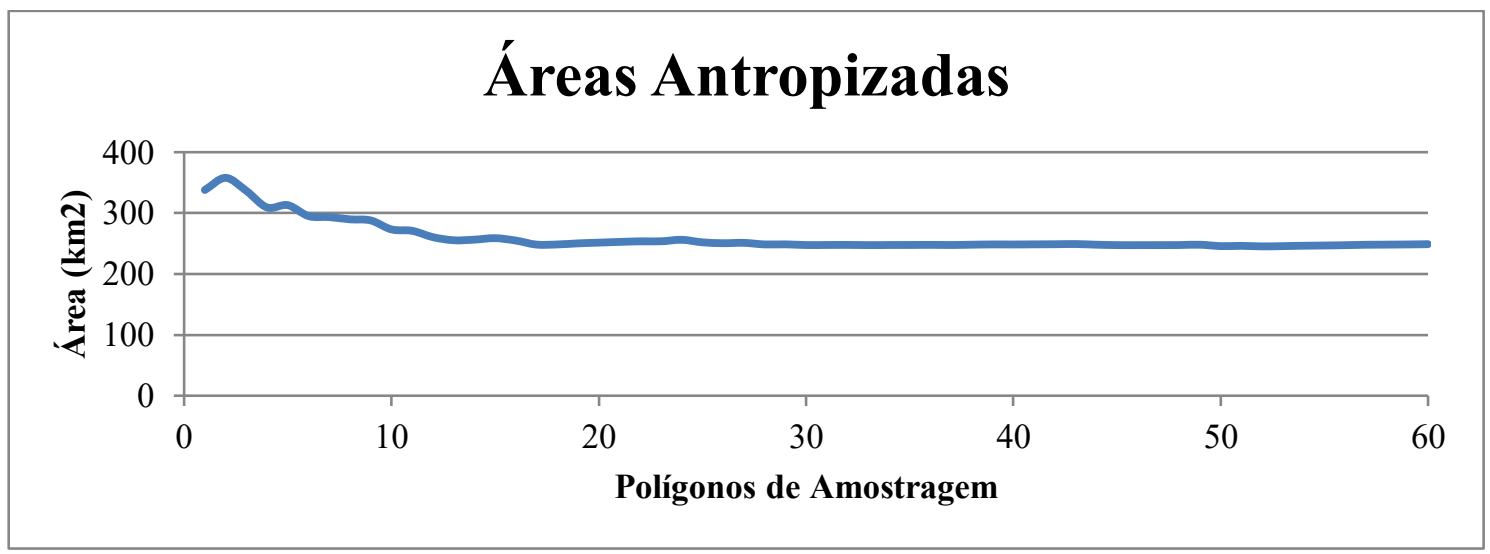

Figura 3 - Áreas Antropizadas

Fonte: Autoria própria, 2019.

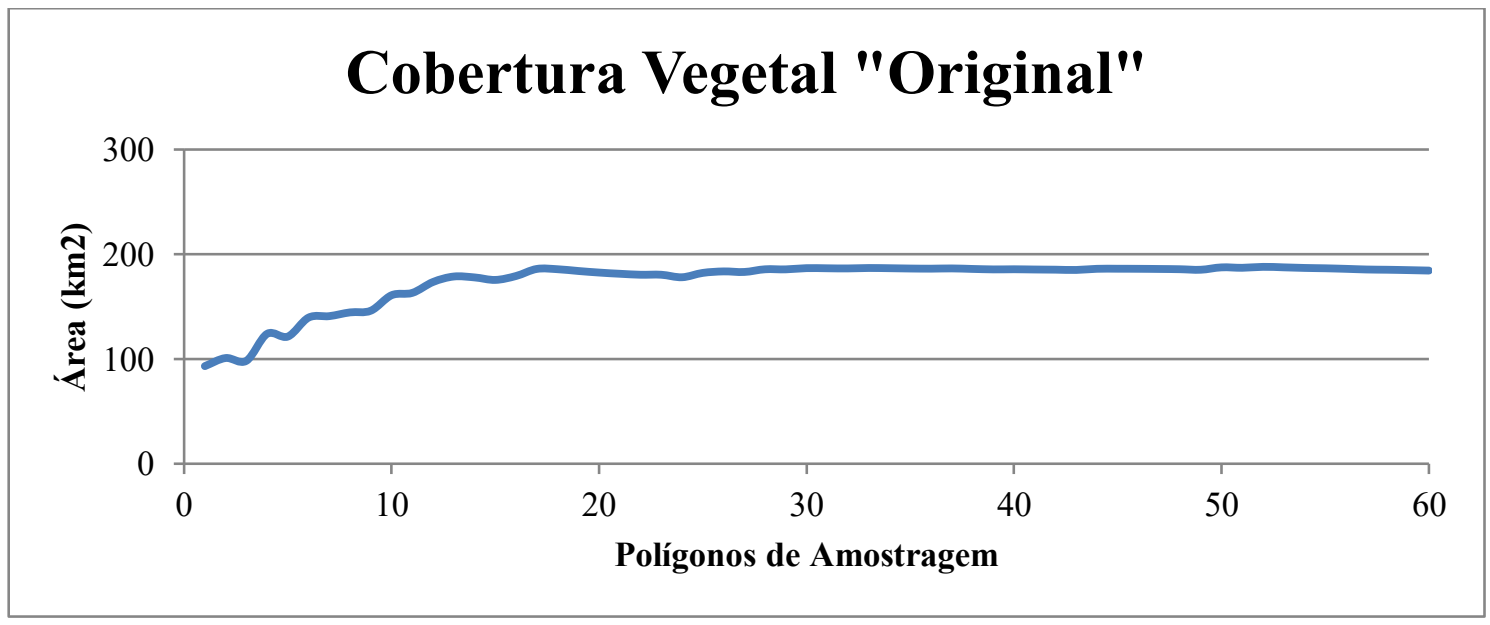

Figura 4 - Cobertura Vegetal "Original" Fonte: Autoria própria, 2019.

A tabela 1 apresenta a distribuição de pixels por classes amostrais para 10, 20, 30, 40, 50 e 60 polígonos ou áreas de treinamento. Como pode ser observado a partir dos dados da tabela 1 , ocorreram variações mesmo quando foram utilizados mais de cinquenta polígonos amostrais. Tais discrepâncias apresentaram, no máximo, variações de cerca de $2 \%$, entre o valor encontrado para as 
sessenta áreas de treinamento, e os maiores e menores valores encontrados para as demais simulações, contadas a partir de vinte polígonos amostrais. Essa situação pode ser explicada pelas próprias características físicas da paisagem, uma vez que variações naturais decorrem da absorção e reflexão maior ou menor de determinado comprimento de onda procedente da radiação eletromagnética. Consequentemente, feições entendidas em dada categoria, no decorrer das diversas inferências, vão perdendo relevância em detrimento de outras e acabam sendo representadas em classes distintas.

Tabela 1 - Distribuição de pixels relativos às classes amostrais adotadas

\begin{tabular}{|c|c|c|c|c|}
\hline POLÍGONOS/CLASSES & $\begin{array}{c}\text { CORPOS } \\
\text { D'ÁGUA }\end{array}$ & $\begin{array}{c}\text { ÁREAS } \\
\text { ANTROPIZADAS }\end{array}$ & $\begin{array}{c}\text { COBERTURA } \\
\text { VEGETAL } \\
\text { “ORIGINAL" }\end{array}$ & TOTAL \\
\hline 10 POLÍGONOS & 49.162 & 303.504 & 178.773 & 531.439 \\
\hline 20 POLÍGONOS & 49.259 & 279.363 & 202.817 & 531.439 \\
\hline 30 POLÍGONOS & 48.919 & 275.008 & 207.512 & 531.439 \\
\hline 40 POLÍGONOS & 49.116 & 275.996 & 206.327 & 531.439 \\
\hline 50 POLÍGONOS & 50.054 & 273.052 & 208.333 & 531.439 \\
\hline 60 POLÍGONOS & 49.960 & 276.553 & 204.926 & 531.439 \\
\hline
\end{tabular}

Fonte: Autoria própria, 2019.

Um mesmo tipo de vegetação, por exemplo, pode apresentar respostas espectrais variadas em função de sua condição fisionômica. Pode-se inferir, desse modo, que uma única árvore tende a exibir uma variação infinita de valores de pixels relativos à sua ramagem. A figura 5 procura retratar esta característica a partir da foto colorida (RGB) de uma pequena amostra da espécie Ficus pumila, conhecida trepadeira utilizada em jardins.

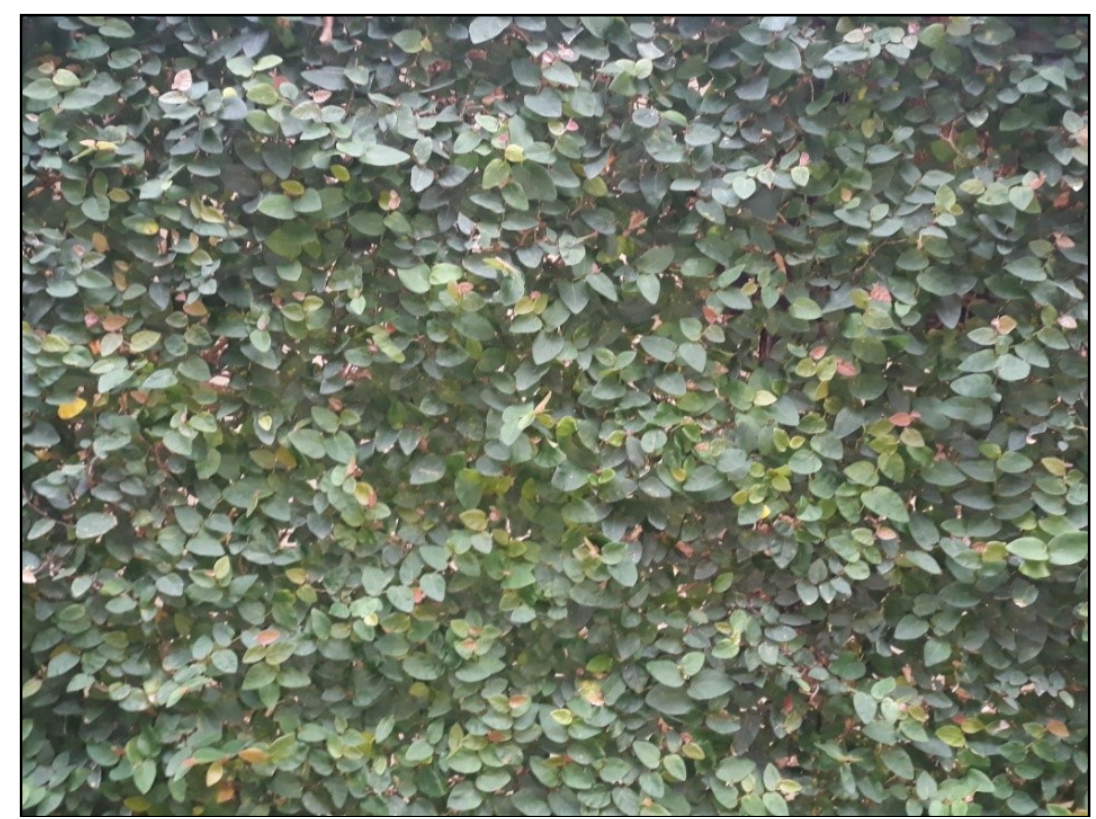

Figura 5 - Amostra de Ficus pumila sp.

Fonte: Autoria própria, 2019. 
Ocorrências como a apresentada estão relacionadas, portanto, ao comportamento espectral das folhas, ou seja,

\begin{abstract}
A baixa reflectância das folhas na região do visível deve-se à absorção da radiação solar pelos pigmentos presentes nos cloroplastos, enquanto que a alta reflectância na região do infravermelho próximo deve-se ao espalhamento da radiação solar no mesófilo, que ocorre devido à interação da radiação solar com a estrutura interna das folhas. Portanto, o comportamento espectral das folhas depende da sua composição química e de sua estrutura interna. (Oliveira et al., 2009, p. 1)
\end{abstract}

Tais considerações se tornam importantes na medida em que a natureza é dinâmica e impossível de ser retratada com total fidelidade na escala trabalhada. Assim sendo, quaisquer variações obtidas em um experimento como o presente não podem ser consideradas inconsistentes. Salienta-se, outrossim, que as classificações realizadas levaram em consideração as características de imagens falsa-cor do sensor OLI do Landsat 8, com o uso da composição 5R-4G-3B, com resolução espacial de $30 \mathrm{~m}$. Neste tipo de combinação, a vegetação mais sadia é traduzida por uma intensa coloração avermelhada.

Com o intuito de analisar os produtos obtidos, procedeu-se à distribuição de pixels relativa a cada uma das classes adotadas para um total de sessenta polígonos amostrais. A tabela 2 a seguir apresenta os valores obtidos para tal simulação.

Tabela 2 - Distribuição de pixels, área e percentuais relativos às classes amostrais

\begin{tabular}{|c|c|c|c|c|}
\hline & $\begin{array}{c}\text { CORPOS } \\
\text { D'ÁGUA }\end{array}$ & $\begin{array}{c}\text { ÁREAS } \\
\text { ANTROPIZADAS }\end{array}$ & $\begin{array}{c}\text { COBERTURA } \\
\text { VEGETAL } \\
\text { "ORIGINAL" }\end{array}$ & TOTAL \\
\hline $\mathbf{N}^{\mathbf{0}}$ DE PIXELS & 49.960 & 276.553 & 204.926 & 531.439 \\
\hline ÁREA TOTAL $\left(\mathrm{km}^{2}\right)$ & 44,964 & 248,898 & 184,433 & 478,295 \\
\hline PERCENTUAL & 9,4009 & 52,0385 & 38,5606 & 100 \\
\hline
\end{tabular}

Fonte: Autoria própria.

Os dados da tabela 2 permitem observar que as áreas antropizadas ocupam mais da metade da superfície total do município, condição sustentada pelo avanço da agropecuária na região. A existência de uma área utilizada para recomposição da floresta nativa (mata atlântica) no Refúgio Binacional (Biológico) de Maracaju, ao sul do município de Mundo Novo, e das áreas de várzea e de ilhas relativas ao Rio Paraná, a leste do mesmo, explicam os mais de 38,5\% referentes à cobertura vegetal "original”. O também significativo percentual alusivo aos corpos d'água, de mais de 9,4\%, são justificados pela presença do caudal do Rio Paraná avultado pela represa da Hidrelétrica de Itaipu, situada à jusante.

A questão central deste estudo, entretanto, estava vinculada ao comportamento dos dados conforme a introdução de polígonos de amostragem na área de trabalho. A tabela 3 apresenta os 
valores correspondentes, respectivamente, às áreas cobertas por 10, 20, 30, 40, 50 e 60 polígonos inseridos na superfície de estudo, de 478,295 $\mathrm{km}^{2}$.

Tabela 3 - Áreas das classes (polígonos), em $\mathrm{km}^{2}$, para amostras de 10, 20, 30, 40, 50 e 60 áreas de treinamento/ polígonos de amostragem.

\begin{tabular}{|c|c|c|c|c|c|c|}
\hline CLASSE & $\begin{array}{c}\text { ÁREAS }\left(\mathrm{km}^{2}\right) \\
10 \text { POL }\end{array}$ & $\begin{array}{c}\text { ÁREAS }\left(\mathbf{k m}^{2}\right) \\
20 \text { POL }\end{array}$ & $\begin{array}{c}\text { ÁREAS }\left(\mathrm{km}^{2}\right) \\
30 \text { POL }\end{array}$ & $\begin{array}{c}\text { ÁREAS }\left(\mathrm{km}^{2}\right) \\
40 \text { POL }\end{array}$ & $\begin{array}{c}\text { ÁREAS }\left(\mathbf{k m}^{2}\right) \\
50 \text { POL }\end{array}$ & $\begin{array}{c}\text { ÁREAS }\left(\mathrm{km}^{2}\right) \\
60 \text { POL }\end{array}$ \\
\hline CORPOS D'ÁGUA & 5,546 & 11,94241 & 18,11934 & 23,92144 & 29,76055 & 36,78528 \\
\hline $\begin{array}{c}\text { ÁREAS } \\
\text { ANTROPIZADAS }\end{array}$ & 15,403 & 37,20494 & 49,1438 & 58,60938 & 69,43421 & 80,57097 \\
\hline $\begin{array}{l}\text { COBERTURA } \\
\text { VEGETAL } \\
\text { "ORIGINAL" }\end{array}$ & 3,947 & 10,91002 & 20,61174 & 30,88708 & 39,22059 & 49,48094 \\
\hline TOTAL & 24,896 & 60,057 & 87,875 & 113,418 & 138,415 & 166,837 \\
\hline
\end{tabular}

Fonte: Autoria própria.

Como pode ser verificada, a agregação de polígonos de amostragem conduz a um consequente aumento de áreas nas três classes propostas. A tabela 4 mostra o percentual dos mesmos polígonos amostrais em relação às áreas totais da classificação realizada para sessenta amostras de cada classe.

Tabela 4 - Percentual das classes para amostras de 10, 20, 30, 40, 50 e 60 áreas de treinamento/polígonos de amostragem em relação às áreas totais da imagem classificada.

\begin{tabular}{|c|c|c|c|c|c|c|}
\hline CLASSE & $\begin{array}{c}\text { 10 POL } \\
\mathbf{( \% )}\end{array}$ & $\begin{array}{c}\mathbf{2 0} \text { POL } \\
\mathbf{( \% )}\end{array}$ & $\begin{array}{c}\text { 30 POL } \\
(\mathbf{\%})\end{array}$ & $\begin{array}{c}\text { 40 POL } \\
(\mathbf{\%})\end{array}$ & $\begin{array}{c}\text { 50 POL } \\
(\mathbf{\%})\end{array}$ & $\begin{array}{c}\text { 60 POL } \\
(\mathbf{\%})\end{array}$ \\
\hline CORPOS D'ÁGUA & 12,3343 & 26,5599 & 40,2974 & 53,2013 & 66,1875 & 81,8105 \\
\hline ÁREAS ANTROPIZADAS & 6,1886 & 14,9479 & 19,7446 & 23,5475 & 27,8967 & 32,3711 \\
\hline $\begin{array}{c}\text { COBERTURA VEGETAL } \\
\text { “ORIGINAL” }\end{array}$ & 2,1401 & 5,9154 & 11,1757 & 16,747 & 21,2655 & 26,8287 \\
\hline TOTAL & 5,2052 & 12,5566 & 18,3725 & 23,713 & 28,9393 & 34,8817 \\
\hline
\end{tabular}

Fonte: Autoria própria.

A tabela 4 permite inferir, de maneira mais elucidativa, que a classe "corpos d'água" foi vetorizada em quase $82 \%$ de sua totalidade, ou seja, aproximando-se substancialmente da realidade em campo. De igual sorte, pode-se constatar que mais de um terço da superfície total trabalhada, contemplando cento e oitenta polígonos amostrais, foi utilizada como "áreas de treinamento".

Com o intuito de comparar os dados, foi realizada uma classificação supervisionada da área que envolve toda a região, a qual contemplava um retângulo com 4650 X 5845 pixels, ou seja, que representam uma área total de $24.461,325 \mathrm{~km}^{2}$. A figura 6 mostra a região abrangida com destaque para o contorno (limite) do município de Mundo Novo.

Esta classificação foi realizada a partir dos mesmos critérios utilizados até agora, isto é, com as mesmas três classes e com sessenta áreas de treinamento. Entretanto, desta feita, os polígonos foram distribuídos aleatoriamente por toda a superfície imageada, de mais de 24 mil quilômetros quadrados. A partir do mapa temático obtido, o qual enquadrava toda a região, foi 
realizado um recorte abrangendo somente a área do município de Mundo Novo (destacado em vermelho na figura 6), objeto dessa nova e específica modelagem, e que representa pouco menos de $2 \%$ da área total. Os resultados obtidos para o recorte podem ser conferidos na tabela 5.

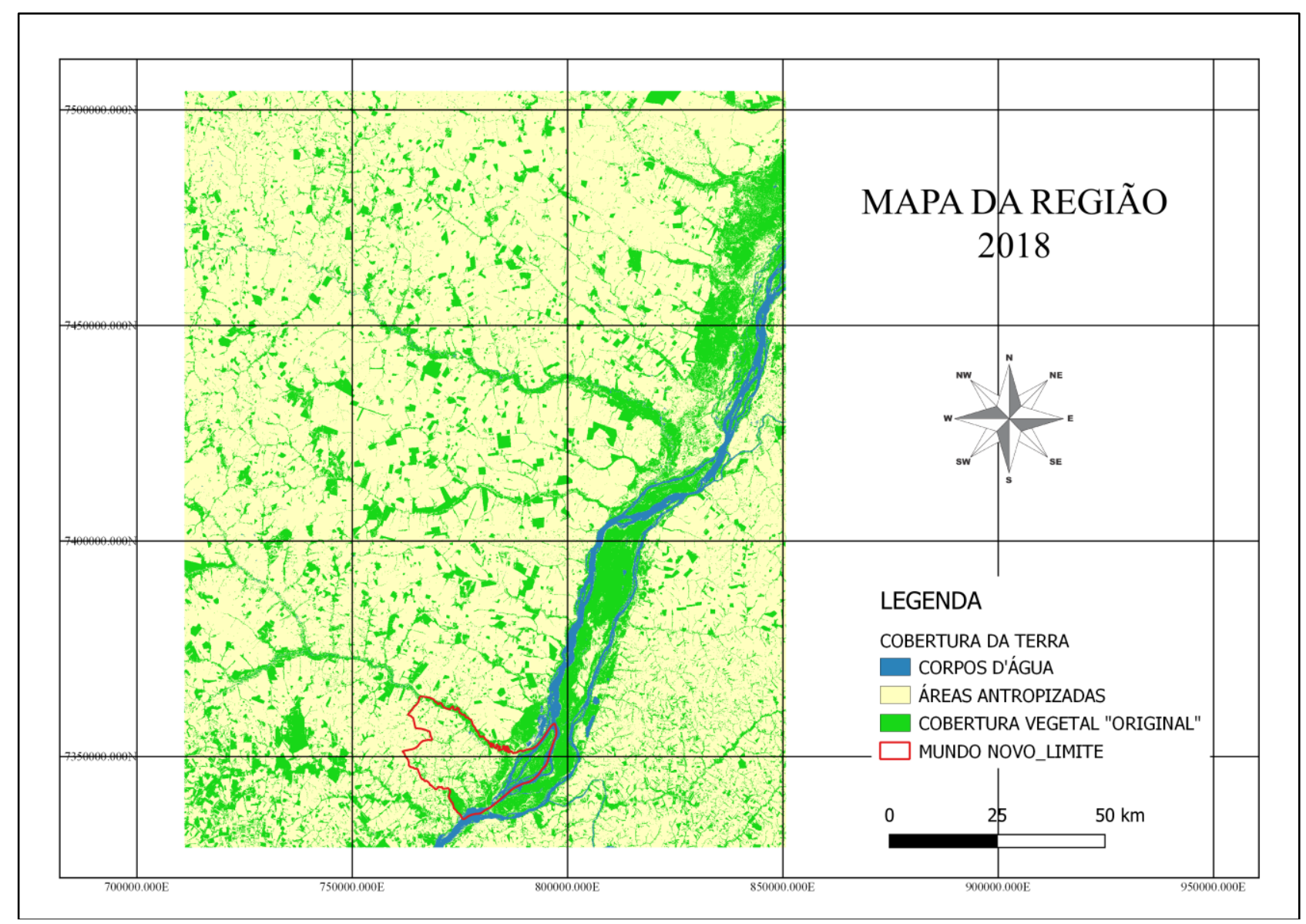

Figura 6 - Mapa da Região.

Fonte: Autoria própria, 2019.

Tabela 5 - Distribuição de pixels, área e percentuais relativos às classes amostrais do recorte.

\begin{tabular}{|c|c|c|c|c|}
\hline & $\begin{array}{c}\text { CORPOS } \\
\text { D'ÁGUA }\end{array}$ & $\begin{array}{c}\text { ÁREAS } \\
\text { ANTROPIZADAS }\end{array}$ & $\begin{array}{c}\text { COBERTURA } \\
\text { VEGETAL } \\
\text { "ORIGINAL" }\end{array}$ & TOTAL \\
\hline $\mathbf{N}^{\mathbf{0}}$ DE PIXELS & 49.701 & 311.713 & 170.025 & 531.439 \\
\hline ÁREA TOTAL $\left(\mathrm{km}^{2}\right)$ & 44,731 & 280,542 & 153,022 & 478,295 \\
\hline PERCENTUAL & 9,3522 & 58,6545 & 31,9933 & 100 \\
\hline
\end{tabular}

Fonte: Autoria própria.

Os dados da tabela 5 permitem a visualização da distribuição de pixels de acordo com cada classe adotada. Com base nesses dados, foi construída a tabela 6, a qual, além de agrupar esses dados, traz os dados da tabela 2 obtidos com a simulação ora proposta, a qual contempla os sessenta polígonos amostrais somente dentro da superfície do município de Mundo Novo. Assim, os dados poderão ser comparados um a um, com relação ao recorte executado em um retângulo maior, onde os polígonos amostrais estavam globalmente distribuídos, e com a simulação realizada, onde as áreas de treinamento foram dispostas somente dentro do perímetro do município de interesse. 
Tabela 6 - Distribuição de pixels, área e percentuais relativos às classes amostrais.

\begin{tabular}{|c|c|c|c|c|c|c|c|}
\hline & \multicolumn{2}{|c|}{ CORPOS D'ÁGUA } & \multicolumn{2}{c|}{$\begin{array}{c}\text { ÁREAS } \\
\text { ANTROPIZADAS }\end{array}$} & \multicolumn{2}{c|}{$\begin{array}{c}\text { COBERTURA } \\
\text { VEGETAL } \\
\text { "ORIGINAL" }\end{array}$} & TOTAL \\
\hline & Recorte & Simulação & Recorte & Simulação & Recorte & Simulação & \\
\hline $\mathbf{N}^{\mathbf{0}}$ DE PIXELS & 49.960 & 49.701 & 276.553 & 311.713 & 204.926 & 170.025 & 531.439 \\
\hline $\begin{array}{c}\text { ÁREA TOTAL } \\
\left(\mathrm{km}^{2}\right)\end{array}$ & 44,964 & 44,731 & 248,898 & 280,542 & 184,433 & 153,022 & 478,295 \\
\hline PERCENTUAL & 9,4009 & 9,3522 & 52,0385 & 58,6545 & 38,5606 & 31,9933 & 100 \\
\hline
\end{tabular}

Fonte: Autoria própria.

Como pode ser depreendido, a partir dos dados da tabela 6, ocorreram variações significativas, de cerca de 6,6\% sobre o total, para as classes áreas antropizadas e cobertura vegetal "original". Essa situação indica algumas dificuldades na identificação de determinadas feições. Espécies exóticas, como as matas de eucaliptos pouco pronunciadas no município de Mundo Novo, estão presentes em razoável quantidade ao longo do retângulo delimitador da área maior, o que pode gerar imprecisões na definição do que foi classificado como cobertura vegetal “original”. A classe corpos d'água não sofreu grande alteração, o que pode ser explicado pela substancial presença do Rio Paraná, tanto numa quanto noutra área de estudo, que conferiu forte caracterização às mesmas.

É importante ser colocado que as classificações começaram a se estabilizar de forma semelhante para ambos os casos, isto é, para o caso do retângulo contemplando $24.461,325 \mathrm{~km}^{2} \mathrm{e}$ para o caso do município de Mundo Novo, com 478,295 km². Para a área maior, considerando toda sua superfície do retângulo, a harmonização da classe corpos d'água, com variações inferiores a $2 \%$, começou a ocorrer a partir da nona área de treinamento, para atingir um equilibro com variações inferiores a $0,5 \%$ somente a partir do $48^{\circ}$ (quadragésimo oitavo) polígono de amostragem. A classe áreas antropizadas experimentou variações significativas, de mais de $2 \%$, até a inclusão do décimo polígono de amostragem, e sua estabilização, com diferenças de menos de $0,5 \%$, ocorreu a partir da inclusão da $37^{\circ}$ (trigésima sétima) área de treinamento. Já a classe cobertura vegetal "original” só se estabilizou ao final, no $56^{\circ}$ (quinquagésimo sexto) polígono de amostragem, quando as desconformidades atingiram valores inferiores a 0,5\%. Para comprovar esta harmonização, foi necessária a inclusão de dez novas áreas de treinamento, num total de setenta polígonos amostrais por classe.

Ao contrário do que se poderia esperar, em geral, a estabilização dos dados relativos às áreas de treinamento correspondente ao município de Mundo Novo, com 478,295 km², iniciou bem mais além do que a classificação realizada para a área maior, de mais de 24 mil quilômetros quadrados. A regularidade em termos de oscilações menores do que $2 \%$ da classe corpos d'água, só iniciou a partir da inclusão do $35^{\circ}$ (trigésimo quinto) polígono amostral, e o equilíbrio mais pronunciado, com variações inferiores a $0,5 \%$, começou a ocorrer a partir da $45^{\text {a }}$ (quadragésima 
quinta) área de treinamento. Com relação à classe 2, relativa às áreas antropizadas, ocorreram variações acima de $2 \%$ até a inclusão de 24 (vinte e quatro) polígonos amostrais. A tendência de estabilização, com oscilações inferiores a $0,5 \%$, somente ocorreram a partir do $57^{\circ}$ (quinquagésimo sétimo) polígono amostral. Finalmente, as áreas contemplando a classe cobertura vegetal "original”, sofreram instabilidades maiores do que $2 \%$ até o $24^{\circ}$ (vigésimo quarto) polígono amostral e sua harmonização, com discrepâncias menores do que $0,5 \%$, se deu tão somente a partir do $58^{\circ}$ (quinquagésimo oitavo) polígono de amostragem. Mais uma vez é importante ser destacado que se fez necessária a inclusão de dez novas áreas de treinamento para comprovar esta estabilização.

\section{CONSIDERAÇÕES FINAIS}

As simulações realizadas não confirmaram a hipótese apresentada. A ideia era a de que, em se tratando de uma área bastante menor, deveria haver uma tendência de estabilização nos dados quando do uso de polígonos de amostragem somente dentro dos limites do município de Mundo Novo, inferior à estabilização alcançada quando do uso da área total da região e posterior recorte. Os resultados obtidos indicaram uma tendência de estabilização bastante próxima àquelas encontradas em uma área bem maior.

Deve-se destacar, no entanto, que a simulação realizada com as amostras contidas tão somente dentro do perímetro do município tende a ser mais precisa do que aquela em que houve o recorte sobre o retângulo abrangendo toda a região, uma vez que abarcava feições presentes somente naquele espaço. Assim sendo, a escala de trabalho é que deve conduzir as necessidades do usuário em relação à sua eficácia.

O caso trabalhado indicou a necessidade de inserção de uma quantidade significativa de amostras e que esta independe da superfície total amostrada. A recomendação de utilizar, ao menos, cinquenta áreas de treinamento por classe que compreendam todas as características relativas às classes a serem adotadas, foi devidamente comprovada nesta área de estudo.

O uso de mais classes poderia conduzir a outros resultados, o que poderá ser objeto de novos ensaios derivados, uma vez que ao se eleger as classes, determinadas áreas de treinamento podem sofrer ajustes ao longo do processo. Reitera-se que o principal desafio, quando da classificação de uma imagem, está diretamente relacionado à cognição de cada usuário, ou seja, em função de sua percepção individual, alguns polígonos englobarão pixels cujas respostas espectrais poderão pertencer a distintas classes. O conhecimento prévio da área de estudo, bem como saídas a campo para checagem das informações, torna-se, portanto, imprescindíveis para um refinamento da modelagem. 
Recomenda-se, finalmente, novos experimentos assemelhados para corroborar os resultados obtidos nesta área de estudo, dentro dos moldes ora adotados. Sempre é bom lembrar que os mapas temáticos derivados deste tipo de simulação são uma aproximação bastante grosseira do comportamento real do ambiente natural.

\section{REFERÊNCIAS}

ARONOFF, Stan. The Minimum Accuracy Value as an Index of Classification Accuracy. Photogrammetric Engineering and Remote Sensing. v. 51, n 1, p. 99-111, 1985.

CONGALTON, Russel G.; GREEN, Kass. Assessing the accuracy of remotely sensed data : principles and practices. 2 ed. CRC Press: Boca Raton, 2009.

CRÓSTA, Alvaro P. Processamento Digital de Imagens de Sensoriamento Remoto. Campinas: Unicamp, 1993.

EASTMAN, J. Ronald. IDRISI for Windows: Introdução e exercícios tutoriais. Porto Alegre, RS: Centro de Recursos Idrisi Brasil - UFRGS, 1998.

FITZ, Paulo R. Geoprocessamento sem complicação. São Paulo: Oficina de Textos, 2008.

FITZ, Paulo R.; VIEIRA, Jeferson C.; SOARES, Mirla C. O uso de polígonos de amostragem em classificações supervisionadas de imagens de satélite. Entre-Lugar. Dourados. v.10, n 19, p. 319$342,2019$.

IBGE. Instituto Nacional de Geografia e Estatística. Divisão Municipal do Brasil. Disponível em: https://mapas.ibge.gov.br/bases-e-referenciais/bases-cartograficas/malhas-digitais. Acesso em fevereiro de 2019.

IBGE. Manual Técnico de Uso da Terra. 3 ed. IBGE: Rio de Janeiro, 2013.

INPE. Instituto Nacional de Pesquisas Espaciais. Imagens do satélite Landsat. Disponíveis em www.inpe.br. Acessos entre março de 2019 e junho de 2019.

LANG, Stefan. A Utilização do Conceito de Totalidade (Holismo) na Geração de Planos de Segmentação Regionalizados em Conjuntos de Imagens de Altíssima Resolução. In: BLASCHKE, Thomas; KUX, Hermann (org.). Sensoriamento Remoto e SIG Avançados. 2 ed. São Paulo: Oficina de Textos, 2009.

MATO GROSSO DO SUL. Semagro. Zoneamento Ecológico-Econômico do Estado do Mato Grosso do Sul - ZEE-MS. 2009. Disponível em: http://www.semagro.ms.gov.br/zoneamentoecologico-economico-de-ms-zee-ms. Acesso em: 17/02/2019.

OLIVEIRA, Luís G. L. de; PEREIRA, Leonardo M.; PEREIRA, Gabriel.;MORAES, Elisabete C.;MAEDA, Eduardo E. Estudo da variabilidade de índices de vegetação através de imagens do 
ETM+/LANDSAT 7. In: XIII Simpósio Brasileiro de Sensoriamento Remoto, 2007, Anais... Florianópolis, INPE, 2007. p. 5995-6002.

RICHARDS, John A.; JIA, Xiuping. Remote Sensing Digital Image Analysis: An Introduction. 4 ed. Berlin: Springer-Verlag, 2006.

USGS. U.S. Geological Survey Imagens do Satélite Landsat. Disponíveis em https://www.usgs.gov/. Acesso entre março de 2019 e junho de 2019.

Trabalho enviado em 17/08/2019

Trabalho aceito em 20/09/2019 